\title{
Influence of Habitat Pollution on Organophosphate Esters and Polycyclic Aromatic Hydrocarbons in Cicadas
}

\author{
Haruki Shimazu ${ }^{1}$ \\ ${ }^{1}$ School of Science and Engineering, Kinki University, Osaka, Japan \\ Correspondence: Haruki Shimazu, School of Science and Engineering, Kinki University, Osaka, 577 8502, Japan. \\ Tel: 81-6-4307-3559. E-mail: hshimazu@civileng.kindai.ac.jp
}

\author{
Received: December 19, 2014 Accepted: January 8, 2015 Online Published: March 30, 2015 \\ doi:10.5539/ep.v4n2p24 \\ URL: http://dx.doi.org/10.5539/ep.v4n2p24
}

\begin{abstract}
The present study examines the concentration levels of seven organophosphate esters (OPEs) and nine polycyclic aromatic hydrocarbons (PAHs) in cicadas and the influence factors of their habitats on the contamination of cicadas. Adult cicadas, nymphal exoskeletons, soils, and saps were sampled in Japan. The total concentrations of seven OPEs and nine PAHs for the adult cicadas ranged from 107 to $8940 \mathrm{ng} / \mathrm{g}$-dw and from 58.9 to $1580 \mathrm{ng} / \mathrm{g}$-dw, respectively. Some OPEs and PAHs were detected in heads, thoraxes, and abdomens of the adult cicadas. The concentrations were higher in the heads than in the other parts. The relationship between OPEs and PAHs in soils and those in cicadas was considerably positive. For some OPEs and PAHs, the concentrations in the saps tend to be higher as those in the cicadas increase. These tendencies indicate that cicadas intake OPEs and PAHs from soils and saps contaminated with these pollutants. The concentrations of OPEs and PAHs tend to increase with those in the atmospheric depositions. This probably shows that OPEs and PAHs in atmospheric depositions pollute soils, and cicadas intake the pollutants from the contaminated soils and saps.
\end{abstract}

Keywords: Japanese cicada, organophosphate esters, polycyclic aromatic hydrocarbons

\section{Introduction}

Organophosphate esters (OPEs) are a group of widely used commercial chemicals such as organic plasticizers, flame retardants, and photographic films. Polycyclic aromatic hydrocarbons (PAHs) are produced primarily as a result of incomplete combustion from anthropogenic sources such as cars, incinerators, and factories. Therefore, the pollutants have been observed in various environments, including surface water (Andresen et al., 2004), sediments (Kawagoshi et al., 1999), air (Nam et al., 2008), and indoor air (Hartmann et al., 2004). The United States Environmental Protection Agency (US EPA) includes some PAHs in the EPA's Priority Chemical List. Anthracene and tri-2-chloroethyl phosphate are included in the Candidate List by REACH in the European Commission. From many perspectives, some countries have regulated OPEs and PAHs because some OPEs and PAHs are considered to be neurotoxic, mutagenic, and carcinogenic (Jamal, 2002; Luch, 2005).

Rachel Carson (1962) pointed out the dangers of widespread use and bioconcentration of chemicals in Silent Spring. Many authors have hitherto reported bioconcentration, bioaccumulation, and biomagnification for various organisms in the laboratory and in the environments (Bruggeman et al., 1984; Muir et al., 1986; Gobas et al., 1989; Debruyn et al., 2004; Kelly et al., 2004; Kondo et al., 2005). For recent studies, Johnson-Restrepo et al. (2008) identified tetrabromobisphenol A and hexabromocyclododecanes in tissues of humans, dolphins, and sharks. Alava J. J. et al. (2009) reported pollutants, such as polychlorinated biphenyls and polybrominated diphenyl ethers in Galapagos sea lions. In relation to the current state, the bioaccumulation regulations including the bioconcentration factor (BCF) and bioaccumulation factor (BAF) have been introduced in the United States, Canada, and Europe. Biomagnification factor (BMF) and trophic or food web magnification factor (TMF) have been discussed as bioaccumulation assessment criteria (Gobas et al., 2009). These factors are associated with bioaccumulation that occurs when organisms are exposed to chemicals in air, water, and their diet. However, they are not associated with bioaccumulation of chemicals in soil. It is necessary to focus on soil contamination of chemicals because the concentrations in soil tend to be high. This study targets cicadas because they spend most of their lives underground as nymphs and may encounter many predators such as wasps and birds. Due to this, cicadas probably bring pollutants in the soil into the food web of the land. 
The objectives of this paper are to determine the concentration levels of the OPEs and the PAHs in cicadas and to investigate the influence factors on the contamination of cicadas from their habitats. In this paper, we analyze OPEs and PAHs in cicadas, soils, and tree saps. Adult cicadas feed saps and nymph cicadas drink root juice. From the comparison between the concentrations, the degree of influence of OPEs and PAHs in soils and tree saps on cicada was evaluated.

\section{Materials and Methods}

\subsection{Cicadas}

Black cicadas (Cryptotympana facialis) were sampled in this study. The black cicada is an insect of the order Hemiptera, suborder Homoptera, in the superfamily Cicadoidea. The cicadas live from the west Japan to the south Japan. The range of the cicada distribution gradually extends to the north. An adult cicada is usually 60 to $70 \mathrm{~mm}$ long including its wings. It is one of the largest species of cicada in Japan.

After mating, the female deposits her eggs into the bark of a twig. When the eggs hatch, the cicada nymphs drop to the ground, where they burrow. Cicada nymphs go through a life cycle that lasts about five years as nymphs for most of their lives. They suck xylem from the roots of tree. Moles, mole crickets, and ground beetles are predators for cicada nymphs. In contrast, the life of an adult cicada ranges from two weeks to one month. Adult cicadas also drink plant sap. They are commonly eaten by spiders, mantises, wasps, and birds.

\subsection{Sample Collection}

Adult cicadas, exoskeletons, soils, and tree saps were collected in Osaka, Japan. Osaka is in a mixed traffic area as well as an industrial, and residential area. Osaka has about 20000 manufacturing business establishments, and a population of 8800000 . There are a lot of main roads such as Kinki expressway with approximately 90000 cars for every twelve hours in the daytime. Seven sampling locations in Osaka were in the campus of Kinki University $\left(34^{\circ} 39^{\prime} 05 \mathrm{~N}\right.$ and $\left.135^{\circ} 35^{\prime} 13 \mathrm{E}\right)$, with an area of $469000 \mathrm{~m}^{2}$.

From August to September in 2011, adult black cicadas and exoskeletons were sampled $(n=30$ and $n=39)$. Four soil samples were collected in November, 2011. They were collected from 0-20 cm depth near the trees from which the exoskeletons were sampled.

From August to September in 2012, adult black cicadas and exoskeletons were sampled $(n=10$ and $n=6)$. Ten adult black cicadas were divided into heads, thoraxes, and abdomens to measure OPEs and PAHs in the individual parts. Three soil samples were collected from 0-20 cm depths in September, 2012. Saps from cherry trees were also sampled in $2012(\mathrm{n}=7)$.

\subsection{OPEs and PAHs}

Seven OPEs and nine PAHs shown in Table 1 are the target compounds in this study because many studies have reported that they are frequently detected in aquatic and airborne environments. Some OPEs and PAHs, for example, TCEP, BaA, BaP, BbF, BkF, DahA, FL and PY, are also designated as hazardous substances that have the potential to harm humans through long-term exposure under Air Pollution Control Law in Japan.

Seven extrapure grade OPEs were purchased from Tokyo Chemical Industry Co., Ltd., Japan, and diluted with acetone and hexane (for pesticide residue and polychlorinated biphenyl analysis from Wako Pure Chemical Industries, Ltd., Japan) to make calibration standards. Nine PAHs of standard material grade were purchased from Wako Pure Chemical Industries, Ltd. and diluted with acetone and hexane to make calibration standards.

\subsection{Analytical Methods and Instruments}

The samples of adult cicada and exoskeleton were dried in a dark place for one month and broken into shatters in aluminum foil by hand. Then, each whole sample was put into a cellulose extraction thimble (Whatman, UK) and extracted with $40 \mathrm{~mL}$ of dichloromethane (for pesticide residue and polychlorinated biphenyl analysis from Wako Pure Chemical Industries, Ltd.) for $15 \mathrm{~min}$ by ultrasonic extraction. The extract was concentrated to $2 \mathrm{~mL}$ with a rotary evaporator. The extract was filtered with a disposable filter device (Whatman, PURADISCTM $25 \mathrm{TF}$ ) and then the extract was concentrated to $0.1 \mathrm{~mL}$ under $\mathrm{N}_{2}$ flow. Hexane was added to the extract to make $2 \mathrm{~mL}$.

The samples of soil and sap were dried in a dark place for one month. Then, $1 \mathrm{~g}$ of the soil or $0.5 \mathrm{~g}$ of the sap was put into a cellulose extraction thimble and extracted with $40 \mathrm{~mL}$ of dichloromethane for 15 min by ultrasonic extraction. The extract was concentrated to $2 \mathrm{~mL}$ with a rotary evaporator. The extract was filtered with a disposable filter device and was concentrated to $0.1 \mathrm{~mL}$ under $\mathrm{N}_{2}$ flow. Hexane was added to the extract to make $2 \mathrm{~mL}$. 
The contents of OPEs and PAHs in these extracts were analyzed using a GC/MS (5975B inert XL E/CI MSD; Agilent technologies, USA) equipped with a HP-5MS capillary column $(30 \mathrm{~m} \times 0.25 \mathrm{~mm}$ i.d., $0.25 \mu \mathrm{m}$ film thicknesses; Agilent technologies, USA). The GC conditions were as follows: splitless injection of $2 \mu \mathrm{L}$; injection port temperature, $250^{\circ} \mathrm{C}$; $\mathrm{GC}$ temperature program, $70{ }^{\circ} \mathrm{C}$ (hold $1.5 \mathrm{~min}$ ) to $180^{\circ} \mathrm{C}$ at $20^{\circ} \mathrm{C} / \mathrm{min}$, and to $280^{\circ} \mathrm{C}$ at $5{ }^{\circ} \mathrm{C} / \mathrm{min}$ (hold $1 \mathrm{~min}$ ); and carrier gas, helium.

The mass spectrometer was operated in the electron impact mode with an electron energy of $70 \mathrm{eV}$. After each pollutant was qualified using three representative fragment ions, it was quantified using the largest one. The quantification was performed by an external calibration method. The recoveries and the variation coefficients for OPEs and PAHs in the pretreatment process for the analysis ranged from $70 \%$ to $120 \%$ and from $7 \%$ to $20 \%$, respectively.

Table 1. OPEs and PAHs measured in this study and their detection limits with the GC/MS

\begin{tabular}{lccc}
\hline \multicolumn{1}{c}{ Chemicals } & Abbreviations & logKow & Detection limits (pg) \\
\hline OPEs & & & 0.72 \\
Tributyl phosphate & TBP & 4.00 & 9.5 \\
Tri-2-butoxyethyl phosphate & TBXP & 3.75 & 5.3 \\
Tri-2-chloroethyl phosphate & TCEP & 1.44 & 3.7 \\
Tris (1,3-dichloroisopropyl) phosphate & TDCPP & 3.65 & 1.4 \\
Triethyl phosphate & TEP & 0.80 & 0.76 \\
Tris (2-ethylhexyl) phosphate & TEHP & 9.49 & 2.5 \\
Triphenyl phosphate & TPP & 4.59 & \\
PAHs & & & 3.5 \\
Anthracene & AN & 4.45 & 1.6 \\
Benzo(a)anthracene & BaA & 5.76 & 1.5 \\
Benzo(a)pyrene & BaP & 6.13 & 1.6 \\
Benzo(b)fluoranthene & BbF & 5.78 & 1.8 \\
Benzo(k)fluoranthene & BkF & 6.11 & 4.0 \\
Benzo(g,h,i)perylene & BghiP & 6.63 & 4.2 \\
Dibenzo(a,h)anthracene & DahA & 6.75 & 0.80 \\
Fluoranthene & FL & 5.16 & 1.0 \\
Pyrene & PY & 4.88 & \\
\hline
\end{tabular}

Note. The abbreviations are used in this study. logKow values were obtained from the website of SRS Inc. The detection limits were calculated from values three times the signal-noise ratio at the baseline of the chromatogram with the GC/MS.

\section{Results and Discussion}

\subsection{Sample Properties}

For the adults of black cicada $(\mathrm{n}=30)$, the arithmetic mean \pm standard error (range) was $60.9 \pm 3.7 \mathrm{~mm}(52-67$ $\mathrm{mm})$ for the length and $0.832 \pm 0.222 \mathrm{~g}(0.49-1.24 \mathrm{~g})$ for the dry weight. The arithmetic means of the length were $59.6 \mathrm{~mm}$ for males $(\mathrm{n}=15)$ and $62.2 \mathrm{~mm}$ for females $(\mathrm{n}=15)$. For the exoskeletons of black cicada $(\mathrm{n}=$ $45)$, the arithmetic mean \pm standard error (range) was $34.0 \pm 2.2 \mathrm{~mm}(29-38 \mathrm{~mm})$ for the length and $0.275 \pm$ $0.056 \mathrm{~g}(0.18-0.54 \mathrm{~g})$ for the dry weight. The arithmetic means of the length were $34.5 \mathrm{~mm}$ for males $(\mathrm{n}=23)$ and $33.6 \mathrm{~mm}$ for females $(\mathrm{n}=22)$.

Ten adults of black cicada were divided into heads, thoraxes, and abdomens, for which the target compounds were measured. The arithmetic mean \pm standard error (range) was $62.4 \pm 2.3 \mathrm{~mm}(60-67 \mathrm{~mm})$ for the length and $1.04 \pm 0.200 \mathrm{~g}(0.77-1.38 \mathrm{~g})$ for the dry weight. The average dry weight was $0.068 \mathrm{~g}$ for heads, $0.543 \mathrm{~g}$ for thoraxes, and $0.278 \mathrm{~g}$ for abdomens. 


\subsection{OPEs and PAHs in Cicadas}

The analytical results for OPEs and PAHs in adult cicadas and exoskeletons are shown in Table 2. Seven OPEs and eight PAHs were detected in the adult cicadas. The median concentration and the range for the total of seven OPEs were $3340 \mathrm{ng} / \mathrm{g}-\mathrm{dw}$ and from 107 to $8940 \mathrm{ng} / \mathrm{g}-\mathrm{dw}$, respectively. Those for the total of nine PAHs were $203 \mathrm{ng} / \mathrm{g}-\mathrm{dw}$ and from 58.9 to $1580 \mathrm{ng} / \mathrm{g}-\mathrm{dw}$. All of the OPEs and PAHs were detected in the exoskeletons. The median concentration and the range for seven OPEs were $470 \mathrm{ng} / \mathrm{g}-\mathrm{dw}$ and from 83.4 to $25700 \mathrm{ng} / \mathrm{g}-\mathrm{dw}$, respectively. Those for nine PAHs were $103 \mathrm{ng} / \mathrm{g}$ - $\mathrm{dw}$ and from 13.9 to $3010 \mathrm{ng} / \mathrm{g}$-dw. The total concentrations of OPEs were higher than those of PAHs in both the adult cicadas and the exoskeletons.

TBP, TEP, FL, and PY were detected in all of the adult cicadas. TEHP and BbF were detected frequently. TBP and FL were detected in all of the exoskeletons. TEP and PY were detected frequently. The highest median concentration value was $1160 \mathrm{ng} / \mathrm{g}-\mathrm{dw}$ for TBXP in the adult cicadas and $220 \mathrm{ng} / \mathrm{g}-\mathrm{dw}$ for TBP in the exoskeletons. The concentrations for the detected OPEs and PAHs in both the adult cicadas and exoskeletons were compared by sex. The difference of the concentrations between male and female was not observed.

Some OPEs and PAHs were detected in the heads, thoraxes, and abdomens of the adult cicadas. Figure 1 shows the median and the range between the 25th percentile and the 75th percentile for TBP, TEP, and TEHP. The OPE concentrations in the heads were higher than those in the other parts. However, the OPE contents were slightly higher in the thoraxes than in the other parts because the weight ratio of thorax in a whole body is about $60 \%$.

Table 2. OPEs and PAHs detected in adult cicada and exoskeleton

\begin{tabular}{|c|c|c|c|c|c|c|}
\hline & \multicolumn{3}{|c|}{ Adult cicada } & \multicolumn{3}{|c|}{ Exoskeleton } \\
\hline & Median* & Range & $\mathrm{DR}^{* *}$ & Median* & Range & $\mathrm{DR}^{* *}$ \\
\hline TBP & 132 & $49.1-2210$ & $30 / 30$ & 220 & $76.5-1400$ & $45 / 45$ \\
\hline TBXP & 1160 & N.D. -8030 & $21 / 30$ & N.D. & N.D.-25 300 & $8 / 45$ \\
\hline TCEP & 30.6 & N.D.-449 & $19 / 30$ & N.D. & N.D.-192 & $21 / 45$ \\
\hline TDCPP & N.D. & N.D.-2110 & $4 / 30$ & N.D. & N.D. -1280 & $7 / 45$ \\
\hline TEP & 47.1 & $23.6-256$ & $30 / 30$ & 48.4 & N.D. -158 & $38 / 45$ \\
\hline TEHP & 285 & N.D.-982 & $24 / 30$ & N.D. & N.D. -843 & $15 / 45$ \\
\hline ТРP & N.D. & N.D.-243 & $7 / 30$ & N.D. & N.D. -140 & $4 / 45$ \\
\hline ¿7OPEs & 3340 & $107-8940$ & $30 / 30$ & 470 & $83.4-25,700$ & $45 / 45$ \\
\hline $\mathrm{AN}$ & 5.10 & N.D.-26.9 & $18 / 30$ & 11.9 & N.D.-84.4 & $29 / 45$ \\
\hline $\mathrm{BaA}$ & N.D. & N.D.-676 & $1 / 30$ & N.D. & N.D.-32.5 & $10 / 45$ \\
\hline $\mathrm{BaP}$ & N.D. & N.D.-1310 & $8 / 30$ & N.D. & N.D. -481 & $9 / 45$ \\
\hline $\mathrm{BbF}$ & 89.4 & N.D.-254 & $28 / 30$ & 17.7 & N.D.-718 & $28 / 45$ \\
\hline $\mathrm{BkF}$ & N.D. & N.D.-19.8 & $1 / 30$ & N.D. & N.D.-305 & $5 / 45$ \\
\hline BghiP & N.D. & N.D. & $0 / 30$ & N.D. & N.D. -428 & $2 / 45$ \\
\hline DahA & N.D. & N.D.-159 & $2 / 30$ & N.D. & N.D. & $0 / 45$ \\
\hline FL & 23.7 & $9.55-69.5$ & $30 / 30$ & 40.9 & $13.9-379$ & $45 / 45$ \\
\hline PY & 13.3 & $6.25-48.6$ & $30 / 30$ & 30.5 & N.D.-317 & $43 / 45$ \\
\hline इ9PAHs & 203 & $58.9-1580$ & $30 / 30$ & 103 & $13.9-3010$ & $45 / 45$ \\
\hline
\end{tabular}

Note. *; N.D. (Not detected) data is included in the calculation of median concentrations. **; DR means the detection rate of OPEs and PAHs. ***; All units are ng/g-dw.

\subsection{OPEs and PAHs in Soils and Saps}

The analytical results for OPEs and PAHs for the soils and saps are shown in Table 3. Five OPEs and nine PAHs were detected in the soils. The median concentration and the range for the total of seven OPEs were $190 \mathrm{ng} / \mathrm{g}-\mathrm{dw}$ and from 54.3 to $828 \mathrm{ng} / \mathrm{g}-\mathrm{dw}$, respectively. Those for the total of nine PAHs were $248 \mathrm{ng} / \mathrm{g}-\mathrm{dw}$ and from 75.7 to 


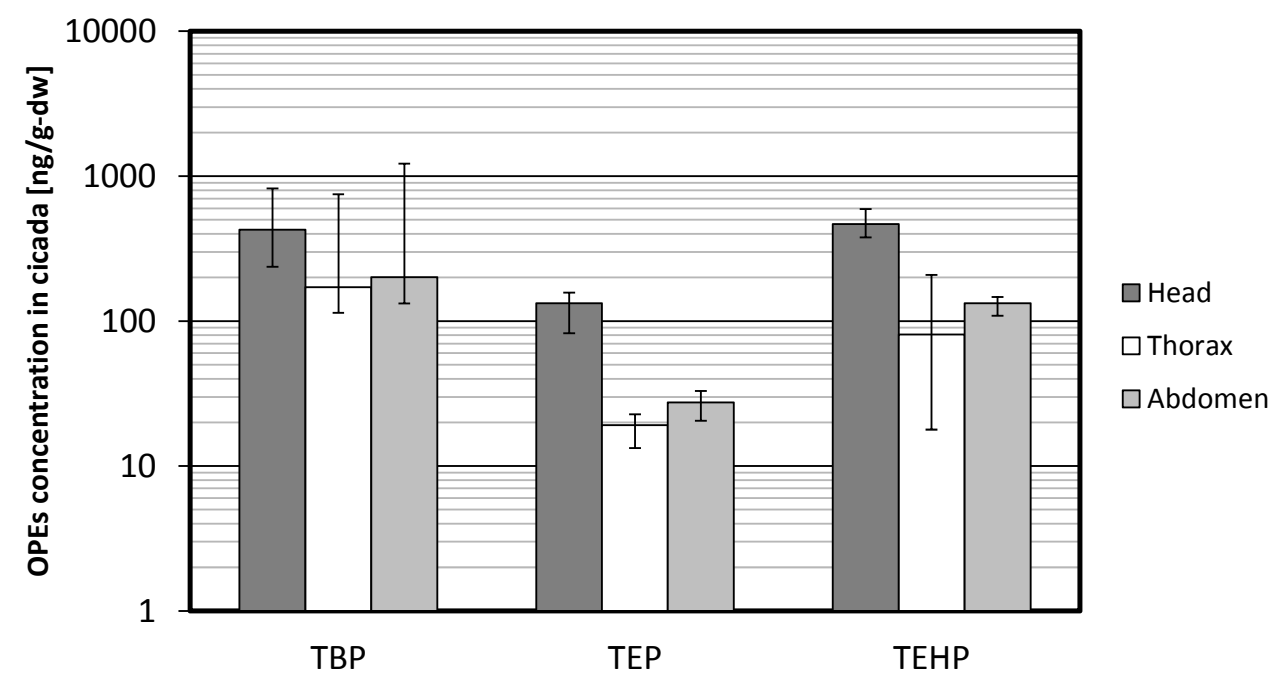

Figure 1. Comparison of OPEs in heads, thoraxes, and abdomens for adult black cicadas

Note. The number of samples is 10 for each part. The detection rates are seven or more. The bars show the median values of the measured concentrations. The ranges show between the 25 th percentile and the 75 th percentile values of the measured concentrations.

Table 3. OPEs and PAHs detected in soil and sap

\begin{tabular}{|c|c|c|c|c|c|c|}
\hline & \multicolumn{3}{|c|}{ Soil } & \multicolumn{3}{|c|}{ Sap } \\
\hline & Median* & Range & $\mathrm{DR}^{* *}$ & Median* & Range & $\mathrm{DR}^{* *}$ \\
\hline TBP & 25.5 & $10.2-79.3$ & $7 / 7$ & 78.5 & $63.2-448$ & $7 / 7$ \\
\hline TBXP & 75.4 & N.D.-775 & $6 / 7$ & N.D. & N.D.-352 & $3 / 7$ \\
\hline TCEP & 5.55 & N.D.-31.6 & $4 / 7$ & N.D. & N.D. & $0 / 7$ \\
\hline TDCPP & N.D. & N.D. & $0 / 7$ & N.D. & N.D. & $0 / 7$ \\
\hline TEP & 6.53 & N.D.-7.18 & $6 / 7$ & 13.7 & $9.93-30.2$ & $7 / 7$ \\
\hline TEHP & 27.8 & N.D.-58.6 & $6 / 7$ & 47.6 & N.D.-131 & $6 / 7$ \\
\hline ТPP & N.D. & N.D. & $0 / 7$ & N.D. & N.D. & $0 / 7$ \\
\hline$\Sigma 7 \mathrm{OPEs}$ & 190 & $54.3-828$ & $7 / 7$ & 338 & $92.2-608$ & $7 / 7$ \\
\hline AN & 5.41 & $0.50-14.3$ & $7 / 7$ & N.D. & N.D. & $0 / 7$ \\
\hline $\mathrm{BaA}$ & 19.9 & $7.93-92.6$ & $7 / 7$ & N.D. & N.D. & $0 / 7$ \\
\hline $\mathrm{BaP}$ & 29.1 & $9.52-117$ & $7 / 7$ & N.D. & N.D. & $0 / 7$ \\
\hline $\mathrm{BbF}$ & 26.4 & $16.2-75.7$ & $7 / 7$ & N.D. & N.D. & $0 / 7$ \\
\hline $\mathrm{BkF}$ & 5.27 & N.D.-37.6 & $4 / 7$ & N.D. & N.D. & $0 / 7$ \\
\hline BghiP & N.D. & N.D.-42.1 & $3 / 7$ & N.D. & N.D. & $0 / 7$ \\
\hline DahA & 3.25 & N.D.-66.4 & $4 / 7$ & N.D. & N.D. & $0 / 7$ \\
\hline FL & 42.1 & $12.7-109$ & $7 / 7$ & 4.20 & $2.80-15.0$ & $7 / 7$ \\
\hline PY & 39.4 & $12.1-104$ & $7 / 7$ & N.D. & N.D.- 6.40 & $2 / 7$ \\
\hline ¿9PAHs & 248 & $75.7-501$ & $7 / 7$ & 4.20 & $2.80-17.3$ & $7 / 7$ \\
\hline
\end{tabular}

Note. *; N.D. (Not detected) data is included in the calculation of median concentrations. **; DR means the detection rate of OPEs and PAHs. ***; All units are ng/g-dw. 
$501 \mathrm{ng} / \mathrm{g}$-dw, respectively. Four OPEs and two PAHs were detected in the saps. The median concentration and the range for the total of seven OPEs were $338 \mathrm{ng} / \mathrm{g}$-dw and from 92.2 to $608 \mathrm{ng} / \mathrm{g}$-dw, respectively. Those for the total of nine PAHs were $4.20 \mathrm{ng} / \mathrm{g}$-dw and from 2.80 to $17.3 \mathrm{ng} / \mathrm{g}$-dw, respectively. The total concentrations for nine PAHs were lower in saps than in the cicadas and soils.

TBP, AN, BaA, BaP, BbF, FL, and PY were detected in all of the soils. TBXP, TEP, and TEHP were detected frequently. TBP, TEP, and FL were detected in all of the saps. TEHP was detected frequently. The highest median concentration value was $75.4 \mathrm{ng} / \mathrm{g}-\mathrm{dw}$ for TBXP in the soils and $78.5 \mathrm{ng} / \mathrm{g}-\mathrm{dw}$ for TBP in the saps.

\subsection{Influence Factors on Cicada Contamination}

To determine the influence of OPEs and PAHs in the soils on cicada contamination, the relationships between the OPEs and PAHs in the soils and those in the cicadas are shown in Fig. 2 (A). The correlation coefficient for the adult cicada was 0.574 . The OPEs and PAHs in the adult cicadas and nymphal exoskeletons tend to be higher as those chemicals in the soils increase. Though there are three chemicals in the adult cicada and three chemicals in the exoskeleton, the median concentrations in the cicadas tend to increase with those in the saps. These tendencies indicate that cicadas intake OPEs and PAHs from soils and saps contaminated with these pollutants.

(A)

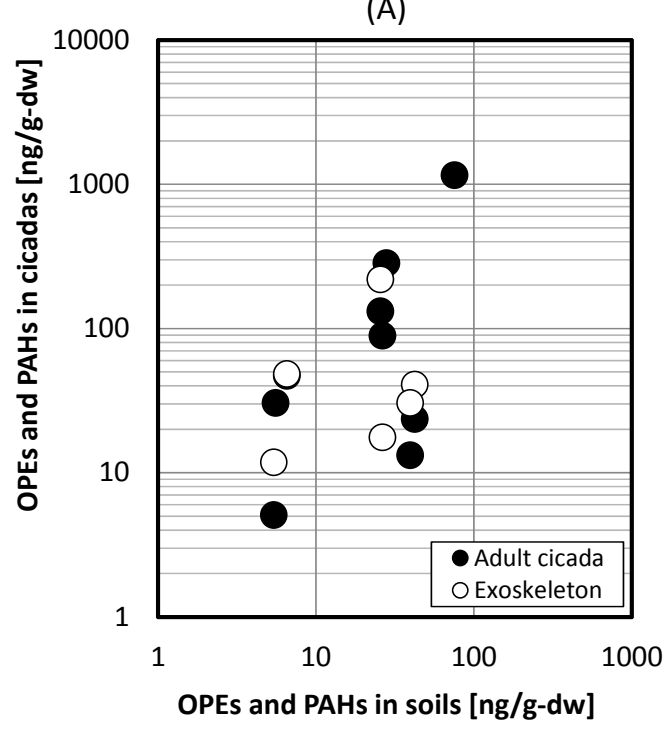

(B)

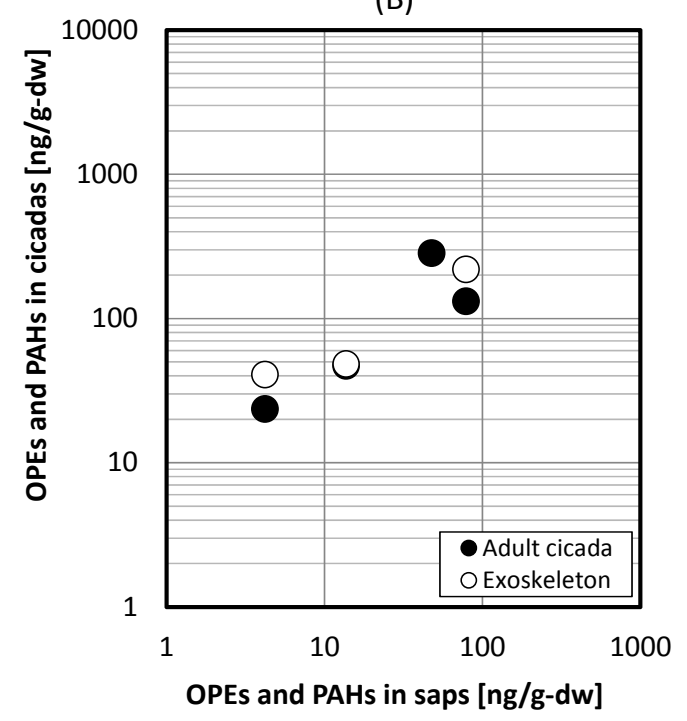

Figure 2. Relationships between the median concentrations for OPEs and PAHs in soils and those in cicadas (A).

Relationship between the median concentrations for OPEs and PAHs in saps and those in cicadas (B)

Note. The median concentrations are calculated including N.D. (Not detected) data. Solid circles indicate the concentrations in adult cicadas. Open circles indicate the concentrations in exoskeletons.

Shimazu (2011) measured OPEs and PAHs in the air and the atmospheric deposition in Osaka, and calculated their surface loadings. The relationship between OPE and PAH surface loadings for non-rainfall time and those concentrations in the soils is shown in Fig.3. The correlation coefficients was 0.619. Significant relationship was observed between the OPE and PAH surface loadings and those concentrations in the soils. This indicates that the atmospheric depositions have an influence on soil contamination. The results of the present study suggest that OPEs and PAHs in the atmospheric depositions pollute soils, and cicadas intake OPEs and PAHs from soils and saps contaminated with these pollutants. 


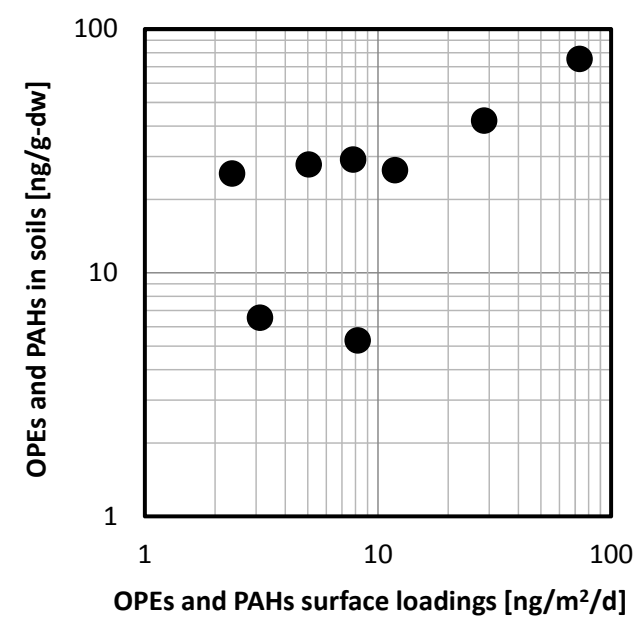

Figure 3. Relationship between the median values of OPE and PAH surface loadings, and the median concentrations for OPEs and PAHs in the soils

Note. The median concentrations are calculated including N.D. (Not detected) data. The OPE and PAH surface loadings are calculated with those concentrations in coarse particulate matter; particle matter $<1.0 \mu \mathrm{m}$ of atmospheric depositions for non-rainfall time (Shimazu, 2011).

\section{Conclusion}

The total concentrations of seven OPEs and nine PAHs for the adult cicadas ranged from 107 to $8940 \mathrm{ng} / \mathrm{g}$-dw and from 58.9 to $1580 \mathrm{ng} / \mathrm{g}$-dw, respectively. Those concentration levels for the exoskeletons were almost same. The patterns of the pollutants were similar between the adult cicadas and the exoskeletons. Some OPEs and PAHs were detected in heads, thoraxes, and abdomens of the adult cicadas. Although the concentrations were higher in the heads than in the other parts, the contents were slightly higher in the thoraxes than in the other parts. The relationship between OPEs and PAHs in soils and those in cicadas was considerably positive. For some OPEs and PAHs, the concentrations in the saps tend to be higher as those in the cicadas increase. These tendencies indicate that cicadas intake OPEs and PAHs from soils and saps contaminated with these pollutants. The concentrations of OPEs and PAHs in the soils tend to increase with those in the atmospheric depositions. This probably shows that OPEs and PAHs in atmospheric depositions pollute soils, and cicadas intake the pollutants from the contaminated soils and saps.

\section{Acknowledgments}

The author would like to thank Kinki University for providing the grant to complete this research. The author acknowledge the assistance given by Kazuya Nagahama and Masayoshi Nakashima.

\section{References}

Alava, J. J., Ikonomou, M. G., Ross, P. S., Costa, D., Salazar, S., Aurioles-Gamboa, D., \& Gobas, F. A. P. C. (2009). Polychlorinated biphenyls and polybrominated diphenyl ethers in Galapagos sea lions (Zalophus wollebaeki). Environmental Toxicology and Chemistry. 28, 2271-2282. Retrieved from http://onlinelibrary.wiley.com/enhanced/doi/10.1897/08-331.1/

Andresen, J. A., Grundmann, A., \& Bester, K. (2004). Organophosphorus flame retardants and plasticisers in surface waters. Science of the Total Environment, 332, 155-166. Retrieved from http://www.sciencedirect.com/science/article/pii/S0048969704003316\#

Bruggeman, W. A., Opperhuizen, A., Wijbenga, A., \& Hutzinger, O. (1984). Bioaccumulation of superlipophilic chemicals in fish. Toxicological and Environmental Chemistry, 7, 173-189.

Carson, R. L. (1962). Silent spring. New York (NY): Houghton Mifflin.

Debruyn, A. M. H., Ikonomou, M. G., \& Gobas, F. A. P. C. (2004). Magnification and toxicity of PCBs, PCDDs, and PCDFs in upriver-Migrating Pacific Salmon. Environmental Science and Technology, 38, 6217-6224. Retrieved from http://pubs.acs.org/doi/pdf/10.1021/es049607w

Gobas, F. A. P. C., Bedard, D. C., Ciborowski, J. J. H., \& Haffner, G. D. (1989). Bioaccumulation of chlorinated 
hydrocarbons by the mayfly hexagenia limbata in Lake St. Clair. Journal of Great Lakes Research, 15, 581-588. Retrieved from http://www.sciencedirect.com/science/article/pii/S0380133089715124

Gobas, F. A. P. C., Wolf, W. D., Burkhard, L. P., Verbruggen, E., \& Plotzke, K. (2009). Revisiting bioaccumulation criteria for POPs and PBT assessments. Integrated Environmental Assessment and $\begin{array}{llll}\text { Management, } & 5, & \text { 624-637. } & \text { Retrieved }\end{array}$ http://onlinelibrary.wiley.com/doi/10.1897/IEAM_2008-089.1/full

Hartmann, P. C., Bürgi, D., \& Giger, W. (2004). Organophosphate flame retardants and plasticizers in indoor air. $\begin{array}{llll}\text { Chemosphere, } & 57, & \text { Retrieved } & \text { from }\end{array}$ http://www.sciencedirect.com/science/article/pii/S0045653504007155

Jamal, G. A., Hansen, S., \& Julu, P. O. O. (2002). Low level exposures to organophosphorus esters may cause neurotoxicity. Toxicology, 181-182, 23-33. Retrieved from http:/www.sciencedirect.com/science/article/pii/S0300483X0200447X\#

Johnson-Restrepo, B., Adams D. H., \& Kannan, K. (2008). Tetrabromobisphenol A (TBBTA) and hexabromocyclododecanes (HBCDs) in tissues of humans, dolphins, and sharks from the United States. Chemosphere, 70, 1935-1944. Retrieved from http://www.sciencedirect.com/science/article/pii/S0045653507012374

Kawagoshi, Y., Fukunaga, I., \& Itoh, H. (1999). Distribution of organophosphoric acid triesters between water and sediment at a sea-based solid water disposal site. Journal of Material Cycles and Waste Management, 1, 53-61. Retrieved from http://link.springer.com/article/10.1007/s10163-999-0005-6

Kelly, B. C., Gobas, F. A. P. C., \& Mclachlan, M. S. (2004). Intestinal absorption and biomagnification of organic contaminants in fish, wildlife, and humans. Environmental Toxicology and Chemistry, 23, 2324-2236. Retrieved from http://onlinelibrary.wiley.com/doi/10.1897/03-545/full

Kondo, T., Yamamoto, H., Tatarazako, N., Kawabe, K., Koshio, M., Hirai, N., \& Morita, M. (2005). Bioconcentration factor of relatively low concentrations of chlorophenols in Japanese Medaka. $\begin{array}{llll}\text { Chemosphere, 61, 1299-1304. } & \text { Retrieved }\end{array}$ http:/www.sciencedirect.com/science/article/pii/S004565350500473X

Luch, A. (2005). The Carcinogenic Effects of Polycyclic Aromatic Hydrocarbons. London: Imperial College Press.

Muir, D. C. G., Yarechewski, A. L., Knoll, A., \& Webster, G. R. B. (1986). Bioconcentration and disposition of 1,3,6,8-tetrachlorodibenzo-p-dioxin and octachlorodibenzo-p-dioxin by rainbow trout and fathead minnows. Environmental Toxicology and Chemistry. 5, 261-272. Retrieved from http://onlinelibrary.wiley.com/doi/10.1002/etc.5620050305/abstract

Nam, J. I., Thomas, G. O., Jaward, F. M., Steinnes, E., Gustafsson, O., \& Jones, K. C. (2008). PAHs in background soils from Western Europe: Influence of atmospheric deposition and soil organic matter. $\begin{array}{llll}\text { Chemosphere, } & 70, & \text { Retrieved } & \text { from }\end{array}$ http://www.sciencedirect.com/science/article/pii/S0045653507009873

Shimazu, H. (2011) Polycyclic aromatic hydrocarbons and organophosphoric triesters in air and atmospheric deposition. Journal of Japan Society of Civil Engineering, Ser.G. 67(7), III_741-III_747 (in Japanese).

SRC Inc. Home page. (2014). http://esc.syrres.com/fatepointer/search.asp

\section{Copyrights}

Copyright for this article is retained by the author(s), with first publication rights granted to the journal.

This is an open-access article distributed under the terms and conditions of the Creative Commons Attribution license (http://creativecommons.org/licenses/by/3.0/). 